\title{
Improvement of energy efficiency of natural gas combustion by applying a homogeneous combustion
}

\author{
Jacek Szymczyk ${ }^{1}$, Ilona Cieślak $^{1}$, Agnieszka Jach $^{1,{ }^{*},}$, Rafał Pyszczek $^{1}$, Andrzej Teodorczyk ${ }^{1}$, \\ and Weiyu $\mathrm{Cao}^{2}$ \\ ${ }^{1}$ Warsaw University of Technology, Institute of Heat Engineering, Nowowiejska 21/25, 00-665, \\ Warsaw, Poland \\ ${ }^{2}$ University of Michigan, Department of Mechanical Engineering, Ann Arbor, Michigan 48109
}

\begin{abstract}
In many heat devices designers and operators meet the problem of low efficiency of combustion and restricted emission standards. This process should be improved to maximize its efficiency and satisfy additional requirements as, for example, uniform temperature fieldin combustion chamber, low noise level or very low NOx emission. These requirements are satisfied by homogeneous combustion. Such combustion method is particularly attractive for the steel or glass industry or power industry based in particular on natural gas. In this paper factors, which have the biggest influence on performance of flameless combustion, are discussed, among others: momentum of fuel and oxidizer, composition of the mixture, the temperature of the inlet gases. Additionally, blind simulations of combustion in a combustion chamber of a furnace are run to assess how high is the influence of these factors individually. Numerical simulations are performed in a CFD code AVL Fire. The detailed chemical kinetics mechanism GRI-mech 3.0 is used for combustion calculations. Calculations results are correlated with experimental data. Blind simulations and experiment provide similar level of $\mathrm{NO}_{\mathrm{X}}$ emission ( 6-8 ppm). Experiments showed that the effect of the addition of ethylene to fuel on emissions of $\mathrm{NO}_{\mathrm{X}}, \mathrm{CO}$, THC is not significant. Similarly, numerical simulations predict that influence of ethylene is negligible. $\mathrm{CO}$, THC and $\mathrm{CO}_{2}$ were on a stable level across all cases. $\mathrm{NO}_{\mathrm{X}}$ emissions increases when mass flow of air and fuel increases due to higher heat release in the same volume, what results in higher temperature of combustion products. When temperature of fuel increases $\mathrm{NO}_{\mathrm{X}}$ level decreases.
\end{abstract}

\section{Introduction}

Restricted emission standards and improvement of efficiency are one of the key issues in combustion. One of the methods which help to fulfil these requirements is homogeneous combustion, often called flameless combustion because of not visible flame front

* Corresponding author: ajach@itc.pw.edu.pl 
in combustion area. Such combustion method is particularly attractive for the steel or glass industry or power industry based in particular on natural gas.

In the literature, flameless combustion (FLOX) has some other names: MILD (Moderate and Intense Low Oxygen Dilution) combustion [1], [2], HPAC combustion (Highly Preheated Air Combustion) [3], HTAC (High Temperature Air Combustion) [4], FDI (Fuel Direct Injection) [5]. Several reviews have also been published [1, 6, 7].
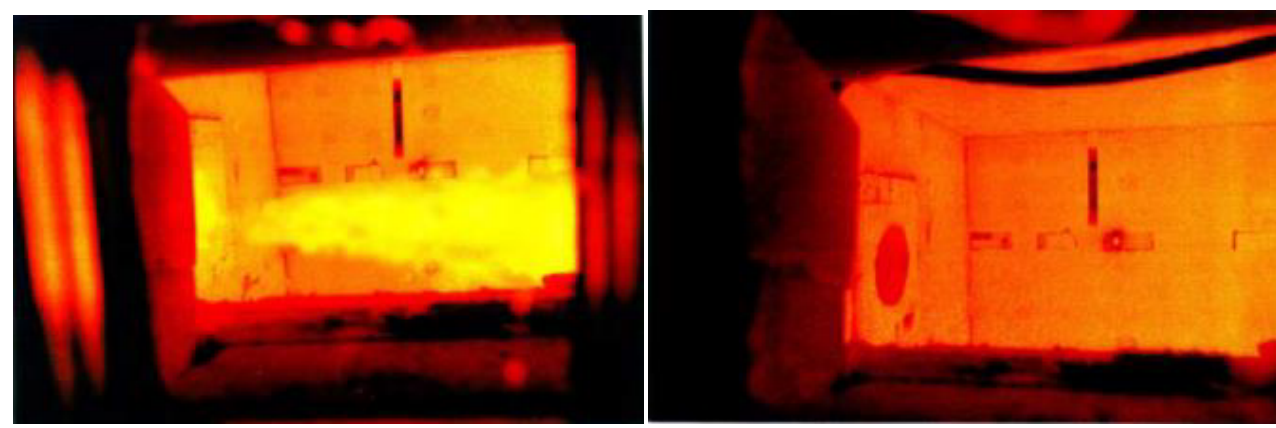

Fig. 1. Comparison flame (left) and flameless (right) firing natural gas [8].

The comparison of flame and flameless combustion is presented in Fig. 1. The difference between conventional flame and flameless combustion is recirculation ratio [9]:

$$
K_{v}=\frac{M_{E}}{M_{F}+M_{A}}
$$

where: $M_{E}$ - mass of exhaust gas, $M_{F}$ - mass of fuel, $M_{A}$ - mass of air

For conventional combustion $K_{v}$ is about 0.3 , but in flameless combustion $K_{v}$ should be more than 2 [7]. Fuel-air equivalence ratio is more than 1 in stable flameless combustion. Flameless combustion occurs when very dilute reactants are preheated to very high temperatures [1].

The main advantage of flameless combustion is reduction of $\mathrm{NO}_{\mathrm{X}}$ emission. Moreover, the researchers noted more homogenous temperature distribution, reduced thermal stress for the burner or less burner faults [10]. Also typical combustion roar disappears due to not visible flame front.

In this paper an experiment performed at University of Michigan in Ann Arbor is described. The influence of doping of ethylene to natural gas on emissions is analyzed. Than blind simulations in a commercial CFD code AVL Fire were performed using the same geometry and boundary conditions. The influence of temperature of fuel, doping of ethylene and mass flow of fuel and air on emissions level $\left(\mathrm{NO}_{\mathrm{X}}, \mathrm{CO}\right.$, THC) was analyzed.

\section{Experimental investigation}

The experimental furnace is installed at University of Michigan in Ann Arbor. It is used mainly for simulation of flameless combustion.

All experiments were run in the vertical, $120 \mathrm{~cm}$ height furnace (Fig. 2a and b). The furnace was built as reversed bucket, where the fuel and oxidizer nozzles were installed vertically on the top of combustion chamber and exhaust gases left the furnace through windows in the lower part. The lowest element of the furnace was a moveable tub with simple heat exchanger made of the copper pipes. The role of heat exchanger was cooling down and - more important - measuring of the radiation level. The water flow was kept 
on a stable level of $0.5 \mathrm{~kg} / \mathrm{s}$. On the top of the combustion chamber one fuel vertical nozzle (in the axis) and four vertical oxidizer nozzles (symmetrical on diameter $560 \mathrm{~mm}$ ) were installed. Each pipeline went through the hood and there was possibility to preheat each of them.

The aim of experiments, among others, was to achieve the temperature field and the content of $\mathrm{O}_{2}$ and pollutants $\left(\mathrm{NO}_{\mathrm{X}}, \mathrm{CO}, \mathrm{THC}\right)$ in each measuring port (probe) on 4 depths on the fuel axis $(\mathrm{r}=0 \mathrm{~mm}), 75,160,230,280 \mathrm{~mm}$ (oxidizer nozzle axis). These probes were installed on the sidewall in three sets, where each set has 5 probes. Fuel flow in the nozzle was $\sim 0.11 \mathrm{~kg} / \mathrm{min}$ and oxidizer $\sim 1.56 \mathrm{~kg} / \mathrm{min}$, fuel and oxidizer nozzles diameter was $16 \mathrm{~mm}$.

During experiments there was a possibility to measure all parameters in 4 levels: in the highest $-220 \mathrm{~mm}, 430 \mathrm{~mm}, 640 \mathrm{~mm}$ and $850 \mathrm{~mm}$ from the top. The lowest probe (1060 $\mathrm{mm}$ from the top) showed on fig. $2 \mathrm{a}$ was not used.

The process of flameless combustion demands under stoichiometric conditions, where the mixture is rich and excess air ratio $\lambda<1$ (equivalence ratio $\varphi=1 / \lambda>1$ ). Starting procedure (about 1 hour) did not allow to keep fixed rich mixture because of safety and the probability of explosion but when temperature reached more than $850^{\circ} \mathrm{C}$ conditions could be slowly changed from lean toward reach mixture. When temperature was higher than minimal $\left(850^{\circ} \mathrm{C}\right)$ flameless combustion could occur.

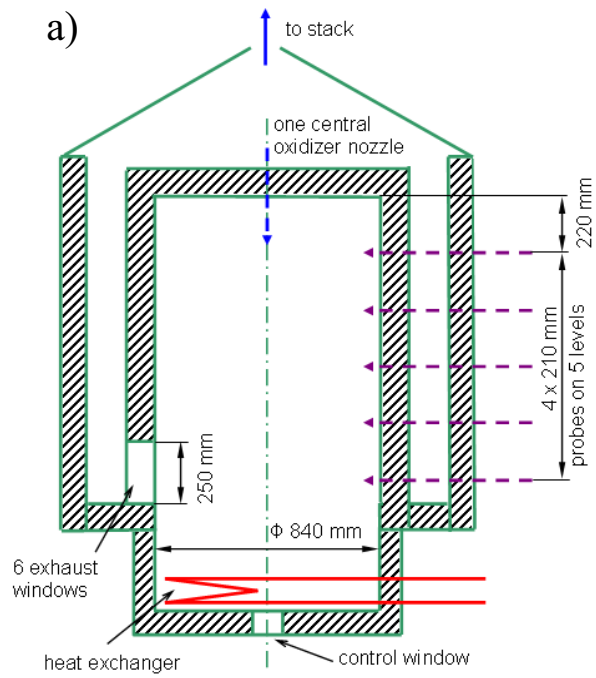

b)

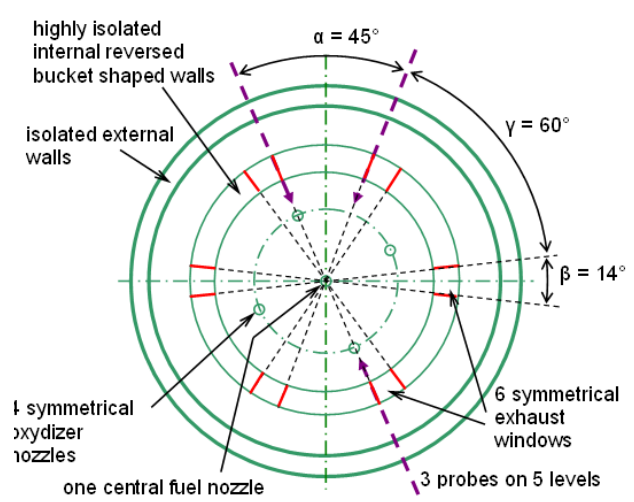

Fig. 2. Testing furnace: $\mathrm{a}-$ vertical view, $\mathrm{b}$ - horizontal view.

The literature $[7,11,12]$ shows that combustion in enhanced oxygen can be more effective and radiation can be stronger compared to combustion in normal air (21\% oxygen and $79 \%$ nitrogen). But the radiation could be enlarged more after adding heavier hydrocarbons to fuel. In this experiment the influence of ethylene doping was investigated. Fuel was preheated up to $473^{\circ} \mathrm{C}$ for radiation enhancement. In Table 1. cases measured during experiment are summarised.

Table 1. Cases measured during experiment.

\begin{tabular}{|c|c|c|}
\hline Name & Oxygen/nitrogen (vol) & Ethylene [\%] \\
\hline 35O2NG & $35 / 65$ & 0 \\
\hline 35O2NG15E & $35 / 65$ & 15 \\
\hline
\end{tabular}


In Fig. $3\left(\mathrm{NO}_{\mathrm{X}}\right)$ the influence of ethylene on $\mathrm{NO}_{\mathrm{X}}$ emissions is shown. Measuring points were located not so close to the top (to fuel and oxidizer nozzles) and one set of points was located straight below fuel nozzle and the second set - straight below oxidizer nozzle. Presented experimental results and results described in [7] show, that for some oxygen/ethylene ratios ethylene can lower $\mathrm{NO}_{\mathrm{X}}$ emission by about $3 \mathrm{ppm}$ in comparison to flameless combustion in pure air. In this case adding ethylene in some levels decreases $\mathrm{NO}_{\mathrm{X}}$ content but on the bottom of the furnace this influence is much smaller probably because temperatures are smaller and the temperature field is more flat. The highest values of $\mathrm{NO}_{\mathrm{X}}$ after ethylene adding were in fuel nozzle stream and they were between around $5 \mathrm{ppm}$ and $6.8 \mathrm{ppm}$ and were similar to the case where ethylene was not added [7]. The highest concentration of $\mathrm{NO}_{\mathrm{X}}$ is on the top and drops when distance from the top $\mathrm{H}$ rises. Overall $\mathrm{NO}_{\mathrm{X}}$ generation during flameless combustion compared to flaming combustion was low (about 1-3 ppm in comparison to 110-130 ppm [7]).

In this case the increase of $\mathrm{NO}_{\mathrm{X}}$ concentration after adding of ethylene can be observed for $\mathrm{H} 1060 \mathrm{~mm}, \mathrm{R} 0 \mathrm{~mm}$ case so this is quite opposite than overall tendency shown in Fig. 3. During the experiment semi-waves of exhaust gases were observed in the combustion chamber what suggests that it was not flameless homogenous combustion. On the other hand, small gradients of temperature and low values of $\mathrm{NO}_{\mathrm{X}}$ show, that it was also not flaming combustion.
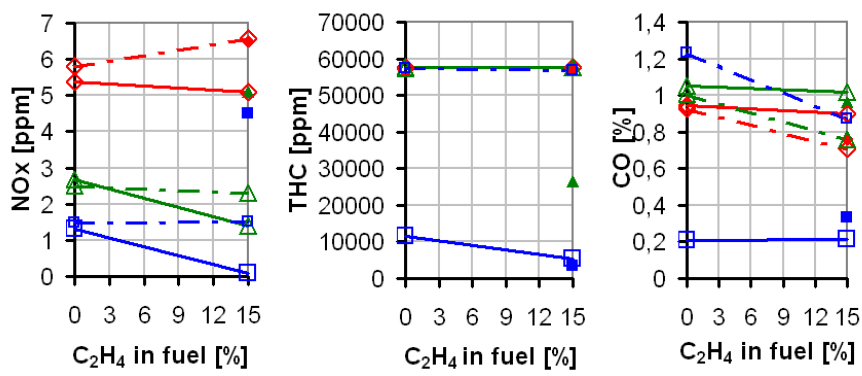

\begin{tabular}{|c|c|c|}
\hline H220 mm; R0 mm (fuel nozzle) & $\mathrm{H} 220 \mathrm{~mm} ; \mathrm{R} 150 \mathrm{~mm}$ & H220 mm; R280 mm (oxydizer nozzle) \\
\hline$\smile \mathrm{H} 850 \mathrm{~mm} ; \mathrm{R0} \mathrm{mm}$ (fuel nozzle) & $\triangle \mathrm{H} 850 \mathrm{~mm} ; \mathrm{R} 150 \mathrm{~mm}$ & —-H850 mm; R280 mm (oxydizer nozzle) \\
\hline$-\diamond-\mathrm{H} 1060 \mathrm{~mm} ; \mathrm{R} 0 \mathrm{~mm}$ (fuel nozzle) & $-\triangle-\mathrm{H} 1060 \mathrm{~mm} ; \mathrm{R} 150 \mathrm{~mm}$ & — घー H1060 mm; R280 mm (oxydizer nozzle) \\
\hline
\end{tabular}

Fig. 3. Concentration of NOx, THC and CO in exhaust gases in dependence on the content of ethylene in the fuel mixture based on natural gas in three distances from the top $\mathrm{H}(220 \mathrm{~mm}$, $850 \mathrm{~mm}$ and $1060 \mathrm{~mm})$ and three radii $\mathrm{R}(0 \mathrm{~mm}, 150 \mathrm{~mm}$ and $280 \mathrm{~mm})$.

In Fig. $3(\mathrm{CO})$ the influence of ethylene on $\mathrm{CO}$ emissions along the furnace radius is also shown. It is observed that the $\mathrm{CO}$ concentration in measuring points is on the low level.

In all measuring points (except for point straight below the oxidizer nozzle) adding of ethylene to fuel decreases $\mathrm{CO}$ concentration. In the oxidizer nozzle stream $\mathrm{CO}$ concentration first is small (near the top) and going down rises to reach nearly similar values independently on radius. Adding of ethylene causes lowering of $\mathrm{CO}$ in one height, but has no influence on the bottom near the outflow windows.

Analysis of THC showed that the concentration profile is flat in almost the whole volume. The only difference is in two points - heights $220 \mathrm{~mm}$ and $850 \mathrm{~mm}$ in oxidizer nozzle stream, $10000 \mathrm{ppm}$. There is observed very large gradient of concentration between $\mathrm{H}=850 \mathrm{~mm}$ and the bottom, and is equal to $125,2 \mathrm{ppm} / \mathrm{mm}$.

It is interesting that there is increase of radiation and efficiency of combustion (in the meaning of transporting heat to heated water) after adding of ethylene. It was observed that the temperature of exit water in heat exchanger rises at a higher value in case $35 \mathrm{O} 2 \mathrm{NG} 15 \mathrm{E}$ unlike case $35 \mathrm{O} 2 \mathrm{NG}$ from $26^{\circ} \mathrm{C}$ to $28.5^{\circ} \mathrm{C}$. This increase is caused by ethylene but also 
by preheating of fuel and oxygen enhancement. Each of these elements can increase intensity of heat generation and radiation but not always causes drop of $\mathrm{NO}_{\mathrm{X}}$ emission.

\section{Simulation}

Numerical simulations of combustion were performed using the AVL Fire code. AVL Fire is the leading CFD simulation tool in the field of combustion analysis. It specializes in the accurate prediction of processes as injection nozzle flow, fuel injection, combustion, emission and exhaust gas aftertreatment.

In this study real geometry of furnace (described in previous section) was investigated. Number of mesh elements and nodes is 368993 and 373305 respectively.

The furnace runs with equivalence ratio of $\mathrm{EQR}=1.15$ (air excess number of $\lambda=0.87$ ). In total 14 simulations were run. Table 2. presents composition of fuel, mass flow of fuel and air $\left(35 \% \mathrm{O}_{2}\right)$, temperature of fuel for each case. Temperature of air was the same in every case and was of $300 \mathrm{~K}$. Temperature of combustion chamber wall was $1100 \mathrm{~K}$, with exception of the bottom wall (a location of a heat exchanger in experiment) - $298 \mathrm{~K}$. Pressure was of 1 bar. The cases: C_a (base case without ethylene) and C_a15_C2H4 ( $15 \%$ of ethylene in fuel) are the most similar to the experimental ones.

The compressibility is solved for a weak compressible flow where density is a function of temperature only. Wall treatment is set to Hybrid Wall Treatment. In this model the "fitting" function between laminar and turbulent part of the boundary layer is derived from the relation of the friction velocity. This wall treatment should ensure a gradual change between viscous sublayer formulations and the wall functions. The default Standard Wall Function heat-transfer model is chosen, as recommended by the AVL Fire manual [15].

Turbulence is a key issue in CFD modeling. In this work turbulence is modeled by using $\mathrm{k}-\zeta$-f turbulence model. The $\mathrm{k}-\zeta$-f model is recommended by the AVL Fire manual for application in combustion simulations [15].

The General Species Transport Module and the General Gas Phase Reaction Module are used to calculate combustion. In this study the GRI-Mech 3.0 was used [13]. This the latest version and most commonly used detailed reaction model for natural gas combustion with 325 reactions and 53 species. The homogeneous chemical reactions are solved in the whole computational domain. The enthalpy sources resulting from the homogeneous reactions are taken into account in the gas-phase enthalpy equation.

Table 2. Analyzed cases (green color informs on a changed value in comparison to the base case).

\begin{tabular}{|c|c|c|c|c|c|}
\hline Case & $\begin{array}{c}\mathbf{\%} \mathbf{C H}_{\mathbf{4}} \\
\text { in fuel }\end{array}$ & $\begin{array}{c}\mathbf{\%}_{\mathbf{2}} \mathbf{H}_{\mathbf{4}} \\
\text { in fuel }\end{array}$ & $\begin{array}{c}\text { Mass flow } \\
\text { fuel }[\mathbf{k g} / \mathbf{s}]\end{array}$ & $\begin{array}{c}\text { Mass flow air } \\
{[\mathbf{k g} / \mathbf{s}]}\end{array}$ & $\begin{array}{c}\text { Temperature } \\
\text { fuel }[\mathbf{K}]\end{array}$ \\
\hline C_a (base) & 100 & 0 & 0.00183062 & 0.0166613 & 760 \\
\hline C_a05 & 100 & 0 & 0.00091531 & 0.0083307 & 760 \\
\hline C_a08 & 100 & 0 & 0.0014645 & 0.0133290 & 760 \\
\hline C_a12 & 100 & 0 & 0.00219674 & 0.0199936 & 760 \\
\hline C_a15 & 100 & 0 & 0.00274593 & 0.0249919 & 760 \\
\hline C_a20 & 100 & 0 & 0.00366124 & 0.0333226 & 760 \\
\hline C_a360 & 100 & 0 & 0.00183062 & 0.0166613 & 360 \\
\hline C_a560 & 100 & 0 & 0.00183062 & 0.0166613 & 560 \\
\hline C_a860 & 100 & 0 & 0.00183062 & 0.0166613 & 860 \\
\hline C_a960 & 100 & 0 & 0.00183062 & 0.0166613 & 960 \\
\hline C_a05_C2H4 & 95 & 5 & 0.00184765 & 0.0166613 & 760 \\
\hline C_a10_C2H4 & 90 & 10 & 0.00186880 & 0.0166613 & 760 \\
\hline C_a15_C2H4 & 85 & 15 & 0.00198900 & 0.0166613 & 760 \\
\hline C_a20_C2H4 & 80 & 20 & 0.00190833 & 0.0166613 & 760 \\
\hline
\end{tabular}



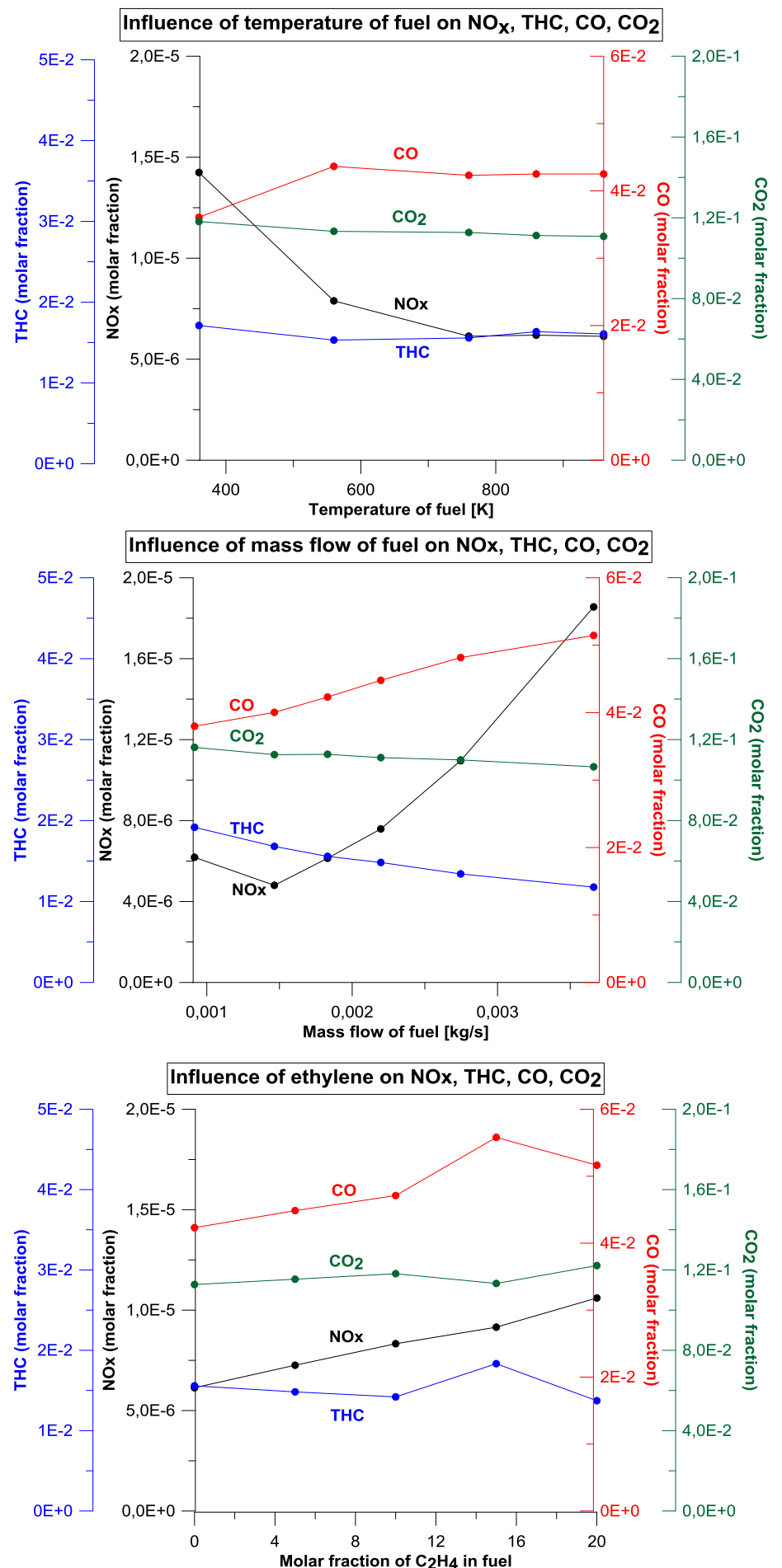

Fig. 4. Influence of temperature of fuel (top), mass flow of fuel (centre) and ethylene doping (bottom) on $\mathrm{NO}_{\mathrm{X}}, \mathrm{THC}, \mathrm{CO}$ and $\mathrm{CO}_{2}$ emissions. 
Results from simulation are presented in Fig. 4 and 5. In Fig. 4. the influences of temperature of fuel, doping of ethylene and mass of fuel on $\mathrm{NO}_{\mathrm{X}}$, THC (Total Hydrocarbon), $\mathrm{CO}$ and $\mathrm{CO}_{2}$ are presented. Emission of $\mathrm{NO}_{\mathrm{X}}$ increases with the increase of mass flow of fuel and ethylene doping. Emission of $\mathrm{NO}_{\mathrm{X}}$ decreases with the increase temperature of fuel, and then stabilizing for temperature of fuel higher than $760 \mathrm{~K}$. Emission of $\mathrm{CO}_{2}$ is almost constant, only slightly decreases for higher mass flow of fuel. Emission of $\mathrm{CO}$ is the lowest for temperature of fuel of $360 \mathrm{~K}$ and the highest for temperature of fuel of $560 \mathrm{~K}$. Further increase of temperature of fuel leads to a stabilization of emission of CO. Emission of $\mathrm{CO}$ increases with the increase of mass flow of fuel and ethylene doping. Emission of THC decreases with the increase of mass flow of fuel. The influence of temperature of fuel and ethylene doping on THC emission is negligible.

Figure 5. (left) presents $\mathrm{NO}_{\mathrm{X}}$ in standard unit $\left(\mathrm{mg} / \mathrm{Nm}^{3}\right)$ to describe emission of furnaces and boilers. Emission limit values for existing medium combustion plants with a rated thermal input equal to or greater than $1 \mathrm{MW}$ and less than or equal to $5 \mathrm{MW}$, other than engines and gas turbines for natural gas is $250 \mathrm{mg} / \mathrm{Nm}^{3}$ [14]. $\mathrm{NO}_{\mathrm{X}}$ emissions in the illustrated furnace is much lower than the limit.

The high influence on mean temperature in combustion chamber (fig. 5. right) has mass flow of fuel. Mean temperature in combustion chamber increases by $174 \mathrm{~K}$ when mass flow of fuel increases fourfold. The effect of temperature of fuel and ethylene doping is negligible.
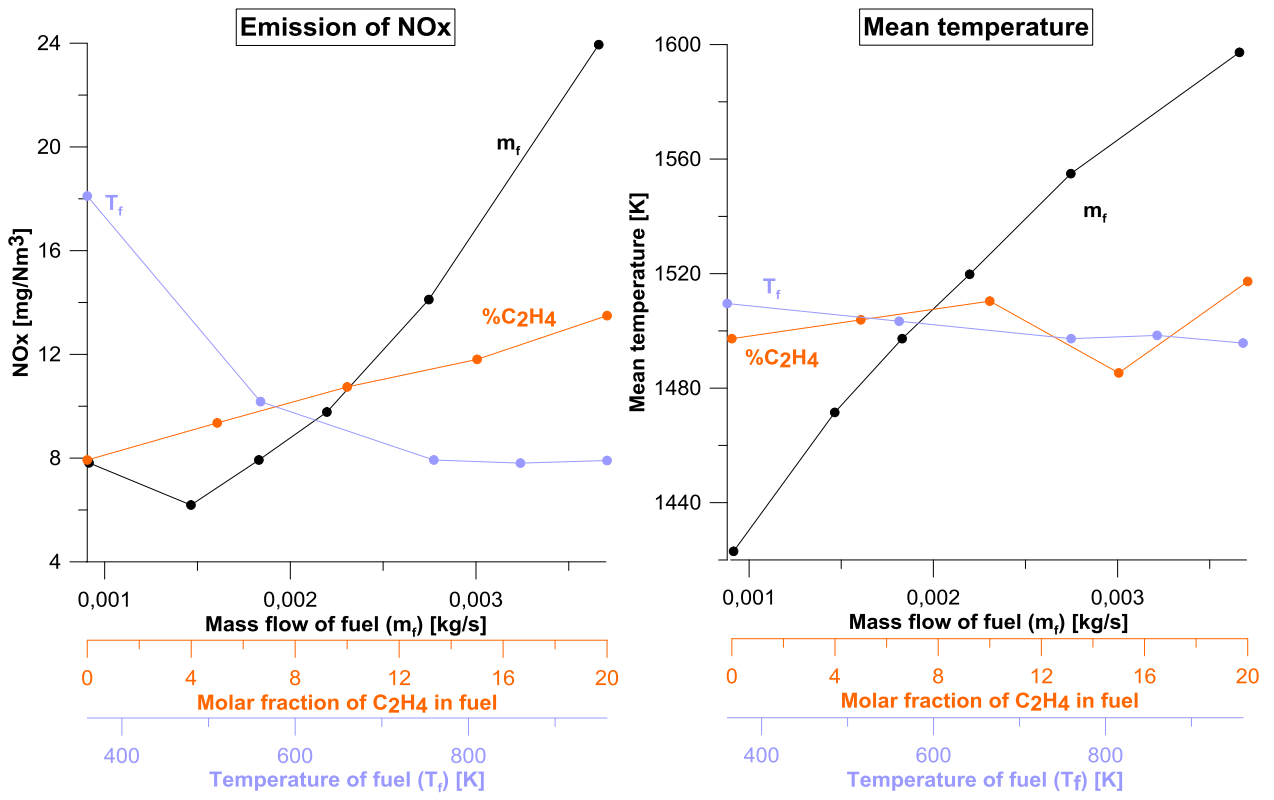

Fig. 5. Influence of temperature of fuel (pastel blue), mass flow of fuel (black) and ethylene doping (orange) on $\mathrm{NO}_{\mathrm{X}}$ emission (left) and mean temperature in combustion chamber (right).

\section{Conclusion}

In the paper experimental and numerical investigations of natural gas combustion in a furnace were performed. The most important conclusion is that blind simulations and experiment provide similar level of $\mathrm{NO}_{\mathrm{X}}$ emission ( $\left.\sim 6-8 \mathrm{ppm}\right)$. Experiments showed that the effect of the addition of ethylene to fuel on emissions of $\mathrm{NO}_{\mathrm{X}}, \mathrm{CO}, \mathrm{THC}$ is not significant. Similarly, numerical simulations predict that influence of ethylene is negligible. 
$\mathrm{CO}$, THC and $\mathrm{CO}_{2}$ were on a stable level across all cases. $\mathrm{NO}_{\mathrm{X}}$ emissions increases when mass flow of air and fuel increases due to higher heat release in the same volume, what results in higher temperature of combustion products. When temperature of fuel increases $\mathrm{NO}_{\mathrm{X}}$ level decreases.

In the next step of numerical investigation influence of equivalence ratio, radiation and recirculation ratio will be assessed.

The authors acknowledge professor Arvind Atreya for support in collecting the data needed to write this article.

\section{References}

1. A. Cavaliere and M. De Joannon, Prog. Energy Combust. Sci. 30 (2004)

2. M. De Joannon, A. Cavaliere, T. Faravelli, E. Ranzi, Proc. Combust. Inst. 30 (2005)

3. M. Katsuki and T. Hasegawa, Symp. Combust. 27 (1998)

4. H. Tsuji, A. K. Gupta, T. Hasegawa, M. Katsuki, K. Kishimoto, M. Morita, High temperature air combustion: From Energy Conservation to Pollution Reduction (CRC Press LLC, 2003)

5. B. A. Fleck, A. Sobiesiak, H. A. Becker, Combust. Sci. Technol. 161 (2000)

6. J. A.Wünning, J. G.Wünning, Prog. Energy Combust. Sci. 23 (1997)

7. J. Szymczyk, P. Olszewski, Arch. Combust. 36 (2016)

8. A. Milani, A. Saponaro, IFRF Combust. J., Article Number 200101 (2001)

9. H. Yu, "Flameless Combustion of Natural Gas in the SJ/WJ Furnace" (2008)

10. J. G.Wünning, Flameless combustion and its applications, 14th IFRF Members Conference (2004)

11. A. Atreya, "Ultra-High Efficiency and Ultra-low Emissions Combustion Tech for Manufact Industries" (2013)

12. N. Krishnamurthy, W. Blasiak, A. Lugnet, Development of High Temperature Air and Oxy-Fuel combustion technologies for minimized $\mathrm{CO} 2$ and NOx emissions in Industrial Heatin, The Joint International Conference on "Sustainable Energy and Environment (SEE)", (2004)

13. G. P. Smith, D. M. Golden, M. Frenklach, N. W. Moriarty, B. Eiteneer, M. Goldenberg, C. T. Bowman, R. K. Hanson, S. Song, W. C. Gardiner, V. V. Lissianski, and Z. Qin, "GRI-mech 3.0 mechanism." http://www.me.berkeley.edu/gri_mech/

14. European Commission, "Directive of the European Parliament and of the Council on the limitation of emissions of certain pollutants into the air from medium combustion plants", Off. J. Eur. Union 442, 19 (2013)

15. AVL FIRE Manual, version 2014.2 